\title{
PEMILIHAN SUPPLIER BERDASARKAN INDEKS KAPABILITAS DENGAN KARAKTERISTIK TUNGGAL
}

\author{
Erik Bagus Prasetvo ${ }^{1}$ dan Nani Kurniati ${ }^{2}$. \\ ,E-mail: erikbagusp@gmail.com \\ Jurusan Teknik Industri, Fakultas Teknologi Industri, Jl. Arif Rahman Hakim Sukolilo, Surabaya, 60111, \\ Indonesia
}

\begin{abstract}
Raw materials is a major requirement in the production process for manufacturing companies. in fulfilling the needs of raw materials for the production process, most manufacturing firms depends on suppliers. Supplier selection is an important part of manufacturing companies. From several supplier selection criteria, quality is one of the important criteria and it used in supplier assessment. Selecting suppliers based on the quality of their products will have a positive impact on manufacturing companies, such as increased profits through reduced operational costs and increased market share. In this study will compare two suppliers at manufacturing companies and choose one that has a higher capability value. The selection of suppliers is made using the yield index of $S_{p k}$ with a single characteristic. Supplier will be selected by comparing the yield ratio of two suppliers. Numerical calculations are performed on suppliers based on $\mathrm{pH}$ levels on the leather. The $\mathrm{pH}$ level on the leather will affect the color. A low $\mathrm{pH}$ may result color degradation earlier, whereas a high $\mathrm{pH}$ may result poor color matching.

(kosong satu spasi tunggal $10 \mathrm{pt}$ )
\end{abstract}

Keywords: supplier selection, quality, $p H$ levels, yield index, single characteristics

\begin{abstract}
Abstrak
Bahan baku merupakan kebutuhan utama dalam melakukan proses produksi bagi perusahaan manufaktur. Dalam memenuhi kebutuhan bahan baku untuk proses produksi, sebagian besar perusahaan manufaktur bergantung pada supplier. Pemilihan supplier merupakan bagian yang penting dalam perusahaan manufaktur. Dari beberapa kriteria pemilihan supplier, kualitas merupakan salah satu kriteria yang penting dan digunakan dalam penilaian supplier. Memilih supplier berdasarkan kualitas produknya akan mempunyai dampak positif terhadap perusahaan manufaktur, seperti peningkatan keuntungan melalui penurunan biaya operasional dan peningkatan pangsa pasar. Pada penelitian ini akan membandingkan dua supplier pada perusahaan manufaktur dan memilih salah satu yang memiliki nilai kapabilitas yang lebih tinggi. Pemilihan supplier dilakukan dengan menggunakan yield index $S_{p k}$ dengan karakteristik tunggal. Supplier akan dipilih dengan cara membandingkan rasio yield dari dua supplier. Perhitungan numerik dilakukan pada supplier berdasarkan kadar $\mathrm{pH}$ terhadap kulit. Kadar $\mathrm{pH}$ pada kulit akan berpengaruh terhadap warna. $p H$ rendah menyebabkan degradasi warna yang lebih awal, sedangkan $p H$ tinggi menyebabkan kesesuaian warna yang tidak baik.
\end{abstract}

Kata kunci: pemilihan supplier, kualitas, kadar $p H$, yield index, karakteristik tunggal

\section{PENDAhuluan}

Perusahaan manufaktur mempunyai hubungan dengan banyak pihak, salah satunya adalah supplier. Supplier adalah perusahaan yang menyediakan material yang 
tidak bisa disediakan oleh perusahaan manufaktur itu sendiri.

Untuk meraih kesuksesannya, perusahaan manufaktur harus mempunyai kemampuan untuk memilih supplier yang tepat. Pemilihan supplier merupakan keputusan mendasar dan kritis bagi perusahaan (Kuo, \& Lin, [4]; Rezaei \& Davoodi, [10]) dalam Wu et al., [12]. Keputusan dalam memilih supplier memberikan dampak secara langsung pada daya saing perusahaan dan mempercepat respon perusahaan terhadap permintaan pasar. Dari berbagai kriteria yang ada, kualitas dianggap sebagai faktor yang paling penting untuk penilaian supplier (Liao et al., [6]). Demikian pula, Weber et al. [11] menganggap kualitas sebagai "extreme importance".

\section{Indeks Proses Kapabilitas dan Process Yield}

Indeks proses kapabilitas telah banyak digunakan untuk mengukur kemampuan proses dan sangat penting untuk kegiatan peningkatan kualitas. Beberapa process capability index yang telah dikembangkan seperti $C_{p}, C_{P U}, C_{P L}$, dan $C_{p k}$ (Kane, [3]).

$$
\begin{aligned}
& C_{p}=\frac{U S L-L S L}{6 \sigma} \\
& C_{p u}=\frac{U S L-\mu}{3 \sigma} \\
& C_{p l}=\frac{\mu-L S L}{3 \sigma} \\
& C_{p k}=\min \left\{\frac{U S L-\mu}{3 \sigma}, \frac{\mu-L S L}{3 \sigma}\right\}
\end{aligned}
$$

Menurut Pearn dan Cheng [9] process yield didefinisikan sebagai persentase unit produk manufaktur dengan karakteristik kualitas yang berada dalam batas spesifikasi. Process yield merupakan kriteria penting yang digunakan dalam industri manufaktur untuk mengukur kinerja proses. Metode untuk mengukur yield untuk proses dengan karakteristik tunggal diteliti secara ekstensif. Namun, metode untuk mengukur yield untuk proses dengan beberapa karakteristik belum banyak dieksplorasi (Pearn et al., [8]. Untuk proses dengan spesifikasi manufaktur dua sisi, process yield dapat dihitung sebagai berikut,

$$
\% \text { Yield }=100[F(U S L)-F(L S L)] \%
$$

dimana $\mathrm{F}($.) adalah cumulative distribution function (CDF) dari karakteristik proses. Jika karakteristik proses mengikuti distribusi normal, maka hasil prosesnya dapat dinyatakan sebagai,

$$
\% \text { Yield }=100\left\{\begin{array}{l}
\phi[(U S L-\mu) / \sigma] \\
-\phi[(L S L-\mu) / \sigma]
\end{array}\right\}
$$

dimana $\mu$ adalah mean prosesnya, $\sigma$ adalah deviasi standar proses, dan $\Phi($.) adalah CDF dari distribusi normal standar $N(0,1)$.

Kemudian Boyles [1] mengusulkan indeks kapabilitas untuk process yield, disebut $S_{p k}$ untuk proses normal, seperti yang didefinisikan sebagai berikut:

$$
S_{p k}=\frac{1}{3} \phi^{-1}\left\{\begin{array}{l}
\frac{1}{2} \phi\left(\frac{U S L-\mu}{\sigma}\right) \\
+\frac{1}{2} \phi\left(\frac{\mu-L S L}{\sigma}\right)
\end{array}\right\}
$$

dimana $\Phi^{-1}($.$) adalah fungsi invers \operatorname{CDF} \Phi$ (.) distribusi normal standar. Menurut (Pearn et al. [7]; Chen [2]), indeks $S_{p k}$ menetapkan hubungan antara spesifikasi manufaktur dan kinerja proses aktual, yang memberikan ukuran yang tepat dari process yield. Jika $S_{p k}$ $=c$, maka process yield dapat dinyatakan sebagai,

$\%$ Yield $=100[2 \phi(3 c)-1] \%$

Indeks $S_{p k}$ memberikan ukuran process yield yang tepat (bukan perkiraan) berdasarkan asumsi normal. Untuk alasan ini, indeks $S_{p k}$ telah diterima oleh banyak digunakan sebagai 
alat komunikasi untuk mengevaluasi dan memperbaiki kualitas manufaktur.

\section{Statistik $S_{p k}$}

Untuk memperkirakan yield index, Lee et al. [5] mempertimbangkan natural estimator sebagai berikut,

$\hat{S}_{p k}=\frac{1}{3} \phi^{-1}\left\{\begin{array}{l}\frac{1}{2} \phi\left(\frac{U S L-\bar{x}}{s}\right) \\ +\frac{1}{2} \phi\left(\frac{\bar{x}-L S L}{s}\right)\end{array}\right\}$

dimana $\quad \bar{x}=\sum_{j=1}^{n} \frac{x_{j}}{n} \quad$ dan $\quad s=\left[\sum_{i=1}^{n} \frac{(x-\bar{x})^{2}}{(n-1)}\right]^{\frac{1}{2}}$ masing-masing adalah mean sampel dan standar deviasi sampel. Distribusi yang tepat dari $\hat{S}_{p k}$ secara matematis sulit diatasi karena ini adalah fungsi kompleks dari statistik $\bar{x}$ dan $s$. Oleh karena itu, Lee et al. [5] memperoleh pendekatan normal terhadap distribusi $\hat{S}_{p k}$ menggunakan teknik ekspansi Taylor. Artinya, estimator $\hat{S}_{p k}$ kira-kira terdistribusi normal dengan mean $S_{p k}$ dan varian $\frac{\left(a^{2}+b^{2}\right)}{\left\{36 n\left[\phi\left(3 S_{p k}\right)\right]^{2}\right\}}$ dimana,

$a=\frac{1}{\sqrt{2}}\left\{\begin{array}{l}3 C_{p}\left(2-C_{a}\right) \phi\left[3 C_{p}\left(2-C_{a}\right)\right] \\ +3 C_{p} C_{a} \phi\left(3 C_{p} C_{a}\right)\end{array}\right\}$

$b=\phi\left[3 C_{p}\left(2-C_{a}\right)\right]-\phi\left(3 C_{p} C_{a}\right), i=1,2, \ldots$

dan $\Phi($.$) adalah probability density function$ (PDF) dari distribusi normal standar.

Berdasarkan pada pendekatan normal terhadap distribusi $\hat{S}_{p k}$ oleh Lee et al. [5], rasio tes statistik $R$ dapat ditunjukkan sebagai berikut,

$R=\frac{S_{p k 1}}{S_{p k 2}}=\frac{N\left(S_{p k 2}, \sigma_{s 2}^{2}\right)}{N\left(S_{p k 1}, \sigma_{s 1}^{2}\right)}, i=1,2, \ldots$

dimana
$\hat{S}_{p k i}=\frac{1}{3} \phi^{-1}\left\{\begin{array}{l}\frac{1}{2} \phi\left(\frac{U S L-\bar{x}_{i}}{s_{i}}\right) \\ +\frac{1}{2} \phi\left(\frac{\bar{x}_{i}-L S L}{s_{i}}\right)\end{array}\right\}, i=1,2, \ldots$,

$\sigma_{s i}^{2}=\frac{\left(a_{i}^{2}+b_{i}^{2}\right)}{\left\{36 n_{i}\left[\phi\left(3 S_{p k i}\right)\right]^{2}\right\}}, i=1,2, \ldots$

$a_{i}=\frac{1}{\sqrt{2}}\left\{\begin{array}{l}3 C_{p i}\left(2-C_{a i}\right) \\ \phi\left[3 C_{p i}\left(2-C_{a i}\right)\right] \\ +3 C_{p i} C_{a i} \phi\left(3 C_{p i} C_{a i}\right)\end{array}\right\}, i=1,2, \ldots$

$b_{i}=\phi\left[3 C_{p i}\left(2-C_{a i}\right)\right]$

$-\phi\left(3 C_{p i} C_{a i}\right), i=1,2, \ldots$

Menurut investigasi yang telah dilakukan oleh Pearn et al. [7] nilai kritis $c_{1}$ dan $c_{2}$ untuk pengujian dua yield indices dapat diperoleh dengan kondisi $S_{p k l}=S_{p k 2}=C$ dan $C_{a 1}=C_{a 2}=1$, contohnya untuk tujuan keandalan.

$$
\begin{aligned}
& P\left(\begin{array}{l}
R<c_{1} \mid S_{p k 1}=S_{p k 2}=C, \\
C_{a 1}=C_{a 2}=1, n_{1}, n_{2}
\end{array}\right) \\
& =\int_{0}^{c_{1}} f_{R}(r) d r=\frac{\alpha}{2}
\end{aligned}
$$

atau

$$
\begin{aligned}
& P\left(\begin{array}{l}
R<c_{2} \mid S_{p k 1}=S_{p k 2}=C, \\
C_{a 1}=C_{a 2}=1, n_{1}, n_{2}
\end{array}\right) \\
& =\int_{c_{2}}^{0} f_{R}(r) d r=\frac{\alpha}{2}
\end{aligned}
$$

Tabel 1 mencantumkan nilai kritis dua sisi $c_{1}$ dan $c_{2}$ dengan $\alpha=0.05$ dan berbagai ukuran sampel $n_{1}=n_{2}=n$ dari 25 sampai 200 dengan kenaikan jumlah sampel sebesar 25 . Jika $R<c_{1}$ atau $R>c_{2}$, maka $H_{0}: S_{p k 2}=S_{p k 1}$ 
= 1 akan ditolak, dan menyimpulkan bahwa yield dari dua proses tersebut berbeda secara signifikan dengan $\alpha=0.05$.

Tabel 1. Nilai kritis $c_{1}$ dan $c_{2}$ dengan $\alpha=$ 0.05 untuk beberapa $n_{1}=n_{2}=n$

\begin{tabular}{ccc}
\hline$n$ & $\mathrm{c} 1$ & $\mathrm{c} 2$ \\
\hline 25 & 0.6668 & 1.4993 \\
50 & 0.7544 & 1.3254 \\
75 & 0.7954 & 1.2570 \\
100 & 0.8206 & 1.2183 \\
125 & 0.8318 & 1.2019 \\
150 & 0.8513 & 1.1745 \\
175 & 0.8617 & 1.1604 \\
200 & 0.8701 & 1.1493 \\
\hline
\end{tabular}

\section{METODE PENELITIAN}

Histogram dibuat dengan batas spesifikasi dua sisi dan plot probabilitas normal dari pengumpulan data $p H$ supplier $\mathrm{A}$ dan supplier B untuk mengetahui posisi dan sebaran data. Langkah berikutnya yaitu menghitung nilai $\hat{S}_{p k}$ dari masing - masing supplier $\hat{S}_{p k A}$ dan $\hat{S}_{p k B}$,

$\hat{S}_{p k i}=\frac{1}{3} \phi^{-1}\left\{\begin{array}{l}\frac{1}{2} \phi\left(\frac{U S L-\bar{x}_{i}}{s_{i}}\right) \\ +\frac{1}{2} \phi\left(\frac{\bar{x}_{i}-L S L}{s_{i}}\right)\end{array}\right\}, i=A, B, \ldots$

$\bar{x}_{i}=\sum_{j=1}^{n} \frac{x_{j}}{n}, i=A, B, \ldots$

$s_{i}=\left[\sum_{i=1}^{n} \frac{(x-\bar{x})^{2}}{(n-1)}\right], i=A, B, \ldots$
LSL lower specification limit

$\bar{x}_{i} \quad$ mean sampel

$s_{i} \quad$ standar deviasi sampel

Untuk membandingkan process yield dari dua supplier, tes hipotesis dilakukan untuk rasio dari dua yield indices sebagai berikut,

$H_{0}: \frac{S_{p k B}}{S_{p k A}}=1$
$H_{1}: \frac{S_{p k B}}{S_{p k A}} \neq 1$

Setelah dilakukan hipotesis kemudian menghitung rasio tes statistik $R$ berdasarkan pendekatan normal terhadap distribusi $\hat{S}_{p k}$

$$
R=\frac{S_{p k B}}{S_{p k A}}
$$

Analisa dilakukan terhadap rasio tes dan nilai kritis dengan $\alpha=0.05$ yang didapatkan dari tabel 1. Untuk menentukan nilai kritis pada tabel 1 disesuaikan dengan jumlah sampel yang digunakan.

Hipotesa berikut dapat digunakan untuk memilih supplier,

$$
\begin{aligned}
& H_{0}: S_{p k B} \leq S_{p k A} \\
& H_{1}: S_{p k B}>S_{p k A}
\end{aligned}
$$

\section{HASIL DAN PEMBAHASAN}

Pada penelitian ini menggunakan data $p H$ dari dua supplier. Masing - masing supplier mempunyai 100 data $p H$. Batasan spesifikasi dari $p H$ kulit yang digunakan antara 3,5 7,5. Tabel 2 dan 3 adalah pengumpulan data kulit $p H$ dari supplier A dan supplier B.

Tabel 2. Pengumpulan data $p H$ supplier $\mathrm{A}$

dimana,

USL upper specification limit 


\begin{tabular}{lllll}
\hline 5.54 & 5.62 & 6.42 & 5.53 & 5.65 \\
5.10 & 5.68 & 5.69 & 6.57 & 5.36 \\
4.90 & 5.74 & 4.35 & 4.82 & 5.41 \\
5.28 & 5.34 & 4.65 & 4.85 & 5.54 \\
5.36 & 5.56 & 5.32 & 6.25 & 5.45 \\
5.66 & 5.46 & 4.85 & 4.54 & 5.14 \\
5.34 & 5.14 & 4.62 & 4.58 & 4.96 \\
5.21 & 4.84 & 5.24 & 5.56 & 4.95 \\
4.58 & 4.98 & 5.62 & 5.55 & 4.85 \\
4.52 & 4.85 & 4.65 & 5.54 & 5.23 \\
4.35 & 5.65 & 4.46 & 4.25 & 4.98 \\
4.52 & 5.95 & 4.65 & 5.24 & 4.65 \\
4.46 & 6.24 & 4.84 & 5.62 & 4.55 \\
4.84 & 6.85 & 4.74 & 5.66 & 4.46 \\
5.84 & 6.47 & 4.81 & 4.92 & 4.85 \\
4.68 & 5.28 & 5.46 & 4.48 & 4.25 \\
4.25 & 5.95 & 5.61 & 4.81 & 3.90 \\
4.95 & 5.64 & 5.66 & 4.96 & 3.85 \\
4.58 & 5.64 & 4.76 & 4.90 & 6.14 \\
5.28 & 5.98 & 5.51 & 5.32 & 5.15 \\
\hline
\end{tabular}

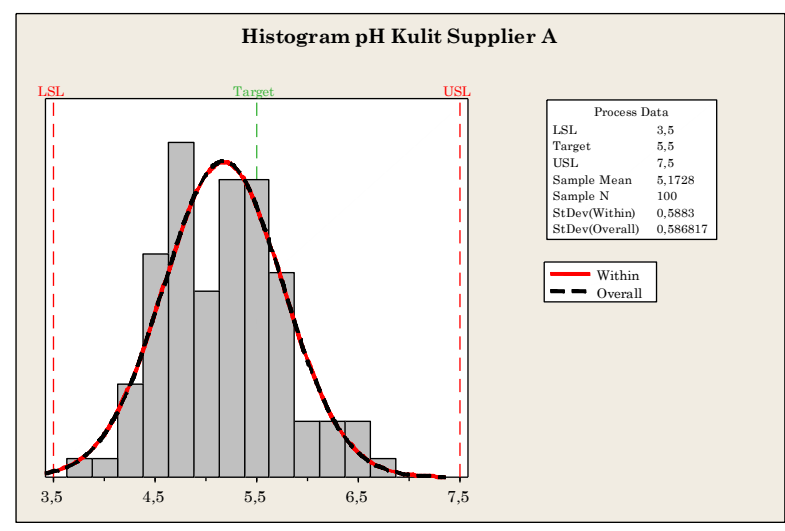

Tabel 3. Pengumpulan data $\mathrm{pH}$ supplier $\mathrm{B}$

\begin{tabular}{lllll}
5.69 & 6.57 & 5.36 & 4.52 & 3.95 \\
4.35 & 4.82 & 5.41 & 6.46 & 6.24 \\
5.36 & 6.42 & 5.95 & 6.65 & 6.85 \\
5.41 & 4.46 & 5.36 & 4.52 & 5.95 \\
3.54 & 4.84 & 5.41 & 4.46 & 6.24 \\
5.45 & 5.84 & 5.54 & 6.44 & 6.87 \\
5.14 & 3.68 & 5.45 & 5.84 & 6.47 \\
4.96 & 4.25 & 5.14 & 4.68 & 5.28 \\
6.99 & 4.95 & 4.96 & 4.25 & 5.95 \\
4.85 & 4.58 & 4.95 & 4.95 & 5.64 \\
5.54 & 5.62 & 6.42 & 5.53 & 4.65 \\
5.15 & 5.68 & 5.69 & 6.57 & 5.36 \\
4.52 & 5.95 & 4.65 & 4.82 & 5.41 \\
6.42 & 4.25 & 4.84 & 4.85 & 3.54 \\
4.84 & 6.90 & 6.74 & 6.25 & 5.45 \\
5.84 & 6.44 & 4.81 & 4.54 & 5.14 \\
4.68 & 5.28 & 3.46 & 4.58 & 4.96 \\
4.25 & 5.95 & 5.61 & 5.56 & 4.95 \\
4.95 & 5.64 & 5.66 & 5.55 & 4.85 \\
4.58 & 5.64 & 4.76 & 5.54 & 5.23 \\
\hline
\end{tabular}

Keasaman pada kulit ditentukan oleh proses pengolahan dari kulit itu sendiri. Kadar $p H$ akan sangat mempengaruhi kualitas dari kulit yang dihasilkan. Degradasi warna yang lebih awal pada kulit disebabkan oleh $p H$ yang rendah, sedangkan kesesuaian warna yang buruk bisa jadi merupakan hasil dari $p H$ yang tinggi. Pada penelitian ini menggunakan batasan dari spesifikasi $p H$ kulit $U S L=7,5$;

Gambar 1. Histogram dari pengumpulan data $p H$ supplier $\mathrm{A}$

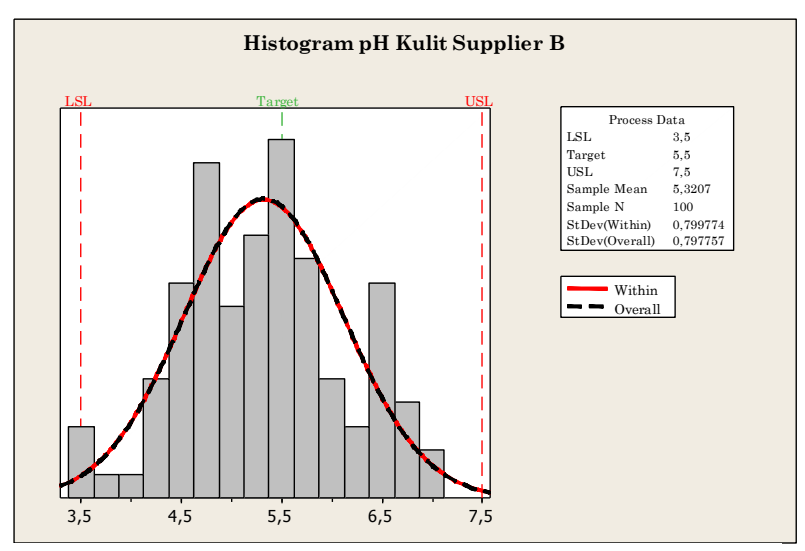

Gambar 2. Histogram dari pengumpulan data $\mathrm{pH}$ supplier $\mathrm{B}$

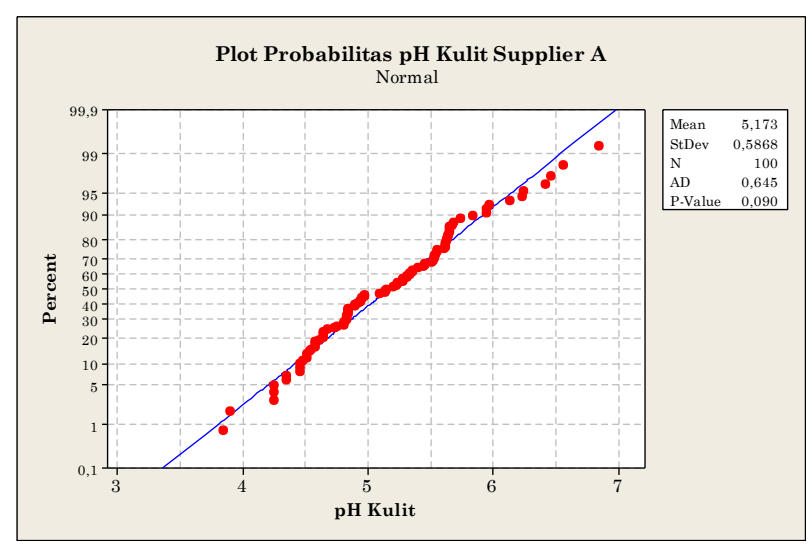

Gambar 3. Plot probabilitas dari data $p H$ supplier A 


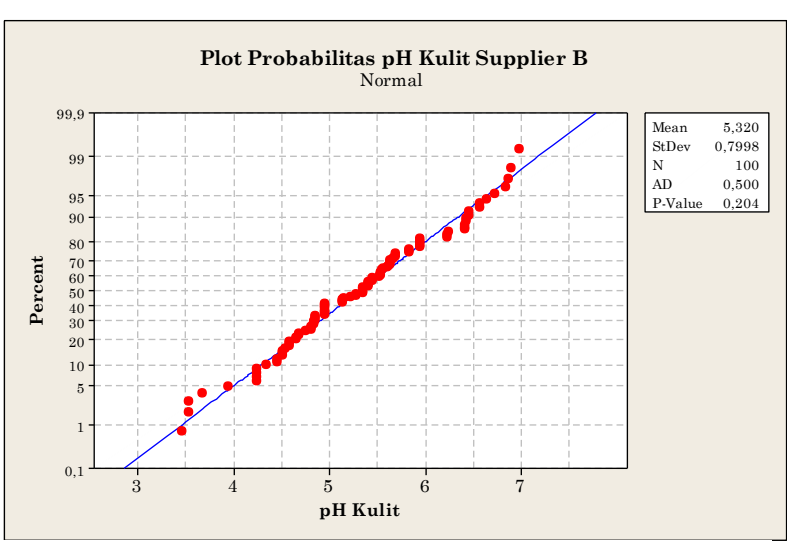

Gambar 4. Plot probabilitas dari data $p H$ supplier B

Gambar 1 dan 2 menunjukkan histogram untuk nilai $p H$ yang dikumpulkan dengan batas spesifikasi dua sisi. Gambar 3 dan 4 menunjukkan plot probabilitas normal dengan uji Anderson-Darling untuk data $p H$ yang dikumpulkan.

Berdasarkan pengukuran di atas, mean sampel, standar deviasi sampel dan nilai estimator $\hat{S}_{p k}$ untuk masing - masing supplier dapat dihitung.

Untuk supplier A, mean sampel, standar deviasi sampel masing - masing adalah $\bar{x}=$ $5,173, s=0,5868$ dan untuk nilai estimator $\hat{S}_{p k A}$ dihitung sebagai berikut,

$$
\begin{aligned}
& \hat{S}_{p k A}=\frac{1}{3} \phi^{-1}\left\{\frac{1}{2} \phi\left(\frac{U S L-\bar{x}}{s}\right)+\frac{1}{2} \phi\left(\frac{\bar{x}-L S L}{s}\right)\right\} \\
& =\frac{1}{3} \phi^{-1}\left\{\frac{1}{2} \phi\left(\frac{7.5-5.173}{0.5868}\right)+\frac{1}{2} \phi\left(\frac{5.173-3.5}{0.5868}\right)\right\} \\
& =1.0198
\end{aligned}
$$

Sedangkan untuk supplier B, mean sampel, standar deviasi sampel masing - masing adalah $\bar{x}=5,320, s=0,7998$ dan untuk nilai estimator $S_{p k B}$ dihitung sebagai berikut,

$$
\begin{aligned}
& \hat{S}_{p k B}=\frac{1}{3} \phi^{-1}\left\{\frac{1}{2} \phi\left(\frac{U S L-\bar{x}}{s}\right)+\frac{1}{2} \phi\left(\frac{\bar{x}-L S L}{s}\right)\right\} \\
& =\frac{1}{3} \phi^{-1}\left\{\frac{1}{2} \phi\left(\frac{7.5-5.320}{0.7998}\right)+\frac{1}{2} \phi\left(\frac{5.320-3.5}{0.7998}\right)\right\} \\
& =0.8158
\end{aligned}
$$

Hipotesis yang digunakan untuk membandingkan process yield dari dua supplier adalah sebagai berikut,

$$
\begin{aligned}
& H_{0}: \frac{S_{p k B}}{S_{p k A}}=1 \\
& H_{1}: \frac{S_{p k B}}{S_{p k A}} \neq 1
\end{aligned}
$$

Sedangkan perhitungan rasio tes statistik $R$ berdasarkan pendekatan normal terhadap distribusi $\hat{S}_{p k}$ adalah,

$R=\frac{S_{p k B}}{S_{p k A}}$

$=\frac{0.8158}{1.0198}$

$=0.7999$

Nilai kritis dua sisi $c_{1}$ dan $c_{2}$ dengan $\alpha=0.05$ dengan nilai sampel $n=100$ masing masing adalah 0.8206 dan 1.2183. Dari nilai rasio di atas diketahui bahwa $R<c_{1}=0.8206$ atau $R>c_{2}=1.2183$ maka $H_{0}$ akan ditolak dan dapat disimpulkan bahwa yield dari dua proses tersebut berbeda secara signifikan dengan $\alpha=0.05$.

Kemudian dilakukan hipotesis untuk memilih supplier berdasarkan yield index $S_{p k}$,

$H_{0}: S_{p k B} \leq S_{p k A}$

$H_{1}: S_{p k B}>S_{p k A}$

Dari hasil yield index $S_{p k}$ diperoleh $S_{p k B}=$ $0,8158<S_{p k A}=1,0198$, maka $H_{0}$ diterima, sehingga dari hasil tersebut dapat diperoleh supplier A yang lebih baik dan akan diprioritaskan. 


\section{KESIMPULAN}

Seleksi supplier yang efektif akan sangat menentukan keberhasilan untuk perusahaan manufaktur. Dari beberapa kriteria pemilihan supplier, kualitas merupakan salah satu kriteria yang diutamakan dalam penilaian supplier. Memilih supplier berdasarkan kualitas produknya akan mempunyai dampak positif terhadap perusahaan manufaktur.

Process yield merupakan kriteria penting yang digunakan dalam industri manufaktur untuk mengukur kinerja proses. Indeks $S_{p k}$ memberikan ukuran process yield dengan batasan spesifikasi dua sisi untuk proses normal dan memberikan pengukuran numerik yang tepat mengenai kinerja proses pada supplier. Ketelitian yang lebih tinggi untuk menilai dua supplier didapatkan dengan menggunakan process yield. Dari perhitungan di atas didapatkan yield index $S_{p k A}=1,0198$ dan $S_{p k B}=0,8158$. Yield index $S_{p k A}$ lebih besar dari $S_{p k B}$, sehingga supplier A yang lebih baik untuk dipilih.

\section{DAFTAR PUSTAKA}

1. Boyles, (1994). Process capability with asymmetric tolerances, Comm. Statist : Simulation Comput. 23 (3) 615-643.

2. Chen, (2005). Comparing four lower confidence limits for process yield index Spk, Int. J. Adv. Manuf. Technol. 26(5-6).

3. Kane, (1986). Process capability indices. Journal of Quality Technology 1986; 18(1):41-52.

4. Kuo \& Lin, (2012). Supplier selection using analytic network process and data envelopment analysis, International Journal of Production Research Vol. 50, No. 11, 2852-2863.

5. Lee et al., (2002). On The Distribution Of The Estimated Process Yield Index Spk, Qual. Reliab. Engng. Int. 2002; 18: 111116.
6. Liao et al., (2012). Fuzzy inference to supplier evaluation and selection based on quality index : a flexible approach, Neural Comput \& Applic.

7. Pearn et al., (2004). Normal Approximation to the Distribution of the Estimated Yield Index Spk, Quality and Quantity 2004; 38(1):95-111.

8. Pearn et al., (2006). Measuring production yield for processes with multiple quality characteristic, International Journal of Production Research Vol. 44, No. 21, 4649-4661.

9. Pearn \& Cheng, (2007). Estimating process yield based on Spk for multiple samples, International Journal of Production Vol. 45, No. 1, 49-64.

10. Rezaei \& Davoodi, (2012). A joint pricing, lot-sizing, and supplier selection model, International Journal of Production Research Vol. 50, No. 16, 4524-4542.

11. Weber et al., (1991). Vendor selection criteria and methods, European Journal of Operational Research 50(1991), 2-18.

12. Wu et al., (2013). Efficient methods for comparing two process yields - strategies on supplier selection, International Journal of Production Research Vol. 51, No. 5, 1587-1602. 